\title{
Does the border matter for health care? A study of medical services provider's location at cities in the Mexican side of the border
}

\author{
¿Es importante la frontera en el debate sobre \\ cobertura de salud? Un análisis de la localización \\ de los proveedores de servicios médicos en el lado \\ mexicano de la frontera
}

José Luis Manzanares Rivera a* (iD (http://orcid.org/0000-0003-3394-4967)

${ }^{a}$ El Colegio de la Frontera Norte, Departamento de Estudios Urbanos y del Medio Ambiente, Ciudad Juárez, Chihuahua, Mexico, e-mail: jlmanzanares@colef.mx

\begin{abstract}
:
This work examines medical services providers' spatial location patterns at the Mexican cities in the us Mexico border as a case study. Formal statistical methods are applied using data sources for each side of the border with the primary source being the National Statistic Directory of Economic Units (DENUE) published by the Mexican Census Bureau. Results identify the following specific medical services activities with particular relative concentrations at the border city scale: private dental offices (NAICS code 621211) CI=1.32, general medicine private offices (NAICS code 621111) CI $=1.16$, private medical diagnostics labs (NAICS code 621511) CI $=1.02$, and private general hospitals (NAICS code 621398) CI $=1.03$. In addition a cluster pattern around border Crossings was found for the largest city included in the study. Results suggest that trans-border health care needs in the region represent a binational integration mechanism with social opportunities for the local populations.
\end{abstract}

Keywords: health care, us Mexico border, cross border demand, poverty.

\section{Resumen:}

En este trabajo se examinan los patrones de localización de los proveedores de servicios médicos en las ciudades fronterizas en el lado mexicano. La metodología se basa en análisis estadístico de microdatos en ambos lados de la frontera, empleando el Directorio Estadístico de Unidades Económicas (DENUE) como fuente primaria. Los resultados permiten identificar las siguientes actividades específicas con alta concentración relativa en las ciudades fronterizas: consul-
This work is licensed under a Creative Attribution-NonCommercial 2.5 Mexico.
CITATION: Manzanares, J. L. (2017). Does the border matter for health care? A study of medical services provider's location at cities in the Mexican side of the border [¿Es importante la frontera en el debate sobre cobertura de salud? Un análisis de la localización de los proveedores de servicios médicos en el lado mexicano de la frontera]. Estudios Fronterizos, 18(36), 151-168, doi: 10.21670/ref.2017.36.a07 
torios dentales del sector privado (NAICs código 621211) $\mathrm{CI}=1.32$, consultorios de medicina general del sector privado (NAICs código 621111) $\mathrm{CI}=1.16$, laboratorios médicos y de diagnóstico del sector privado (NAICs código 621511) CI $=1.02$, otros consultorios del sector privado (NAICs código 621398) CI $=1.03$. Adicionalmente para la ciudad de mayor tamaño en la muestra estudiada, se determinó la existencia de un cluster alrededor de los cruces fronterizos. Los resultados sugieren que las necesidades de servicios médicos transfronterizas en la región representan mecanismos de integración binacional con oportunidades sociales para la población local.

Palabras clave: cuidado de la salud, frontera México-EE.Uu., demanda transfronteriza, pobreza.

\section{Introduction}

Does the border matter for health care? The present work analyzes this question identifying medical services provider's spatial location patterns emerging in the Mexican cities at the us Mexico border as a case study.

Although this two countries, share cultural tides that trace back for more than four hundred years and in many cities along the region also similar demographic profiles, each subregion in the border states faces particular social challenges from which access to health care has become a key social concern.

During the last decade, border studies literature has documented factors determining health care demand across many border cities in the world (Bustamante, Laugesen, Caban \& Rosenau, 2012; Footman, Knai, Baeten, Glonti \& Mckee, 2014). In Europe, crossing borders for health care may be regarded as the rule rather than an exception and a new generation of Europeans sees national frontiers as increasingly irrelevant (McKee \& Belcher, 2008, p.124; Tscheulin \& Drevs, 2007). However this may not be the case at the borders between countries in the new continent.

For one hand, some scholars regard borders as barriers that generate distortions in markets (Sohn \& Lara-Valencia, 2013), however borders may also act as a mechanism to complement consumption in specific services, this connection bears particular character for the us Mexico Border, where a growing medical service sector in the Mexican cities adjacent to the us border provide a relevant aspect of trans border integration that claims particular attention (Bastida, Brown \& Pagán, 2008).

Although, classical contextual determinants of health care demand along the us Mexico Border communities include economic forces such as household income levels and price differentials that are further reinforced by exchanges rates movements (Wallace, Mendez-Luck \& Castañeda, 2009), other developing determinants such as the growing treat of disease proper to the population structure or public policy changes like those set forth by the Afordable Care Act (ACA), have the potential to increase local integration forces providing additional evidence to support the hypothesis that the us Mexico border acts in many social issues as a complement rather as barrier. A view that challenges the borderlands traditional conceptualization centered on administrative and political limits.

From the perspective of cities in the Mexican side, a key premise of this paper is that developing contextual factors may influence local integration by generating additional opportunities to provide medical services for business at the Mexican side 
of the border aiming to cover the health care demand generated by the us border residents; following Sassen (2013) global cities concept, these are dynamics that get territorialized and claim a rather nontraditional conceptualization of border and national territory, furthermore following Anzaldúa (1999) and Rosaldo (1993) in this regard, borders represent sites of potentially transformative cultural hybridity, a rather non classic approach that allows to set a framework to understand health care as a binational process.

The aim of this study is to analyze medical services providers' spatial location patterns at Mexican border cities in an effort to understand how medical services demands, triggered by contextual factors at the us Mexico border, translate into economic opportunities that reflect trans-border integration mechanisms.

It is argued that local level data may provide evidence to support the view of the border as a complement rather as barrier, and contextual factors such as regional health care needs or the evolving health care policy agenda may foster a growing medical service sector in the Mexican cities adjacent to the us border.

\section{Medical services demand at the border}

Research on the social conditions at the us Mexico border, indicates that health care services and patients quite frequently cross the us Mexico border (Jabbari et al., 2015; Su, Pratt, Salinas, Wong \& Pagán, 2013) with a particular strong demand flowing in a north to south direction. The study of determinants of such an empirical regularity has identified economic factors as a main driver. As has been extensively documented by Clemans-Cope, Long, Coughlin, Yemane \& Resnick (2013); Damianov \& Pagán, (2013); Andersen \& Newman (2005) and others, income levels are a key health care access determinant in the United States.

Thus, a financial barriers hypothesis has become a traditional research line to explain medical services demand and the increase in public insurance affiliation for programs such as Medicaid which seeks to improve access for lower income households. While recent studies by Escarce and Kapur (2006, p. 412) show that particular population groups living around the us border such as the Mexican American community face important access constraints, less attention has been directed to understand how this relationship influence cross border demand and the consequences of such demand from a spatial perspective at a local scale, in particular questions remain on medical services providers spatial location patterns emerging in the Mexican cities as a result of such social border dynamics.

Thus analyzing the location pattern of medical service providers at Mexican border cites may contribute to explain border integration mechanism in which health needs and economic opportunities interact.

Early studies by Maril (1989) documenting health insurance restrictions at the us Mexico border, called the attention for particular population groups. The poorest of the Americans, as the author refers to the population living in the eastern part of the us Mexico border face adverse conditions in terms of basic services that reflect a clear disparity among border residents.

Cross border medical services demand has been documented before by academics using an empirical perspective, reflecting the increasing interest by society to explain 
relevant integration opportunities, although their analysis highlights that proximity to the border may be a key feature that provide an alternative strategy to care given the prevailing access barriers in some us border regions (Ortiz, Arizmendi \& Cornelius, 2004), results from that research line, suggest that there are strong market forces driving this practice reinforced by favorable price differentials and other economic asymmetric conditions on the us Mexico border.

According to Whiteman, (2011) this trend has been contributed to by some major United States insurers, such as Blue Shield of California, which in 2000 was the first U.S.-based health plan to offer cross-border health services in Mexico (Whiteman, 2011). ${ }^{1}$

From a public policy perspective, however, an emerging health care agenda aiming to increase access to care for particular vulnerable groups may have a particularly important role considering the southern us border, ${ }^{2}$ where Mexican origin population, accounts for $91 \%$ of the total in some remote areas such as the lower Rio Grande Valley, Texas, and no less than 79\% (United States Census Bureau, 2015) in the whole Texas, Mexico border.

Furthermore, considering health care demand from a theoretic perspective, it has been hypothezed that borders also shape population health (Krueger, Bahloo \& Vaillancourt, 2009), with parallel cultural backgrounds resulting in the development of similar health outcomes, therefore generating an homogeneous medical services demand despite the existence of political borders in a particular region. ${ }^{3}$ Moreover, health management strategies for some diseases require a regular treatment schedule over the patient's lifetime, which may add incentives for cross border demand. ${ }^{4}$ According to empirical evidence provided by Jabbari et al., (2015) in relation to the dynamics of cancer health care at the border: "...the relative paucity of radiation therapy and other oncologic services in the Baja California (Mexico) region, contribute to the increased need for binational collaborations in oncology across the us-Mexico border" (Jabbari et al., 2015, p. 1).

Although, empirical evidence suggest that particular health care needs arising from existing and developing health treats contribute to an increasing drift towards binational integration in health care across the us-Mexico border, little is known on how this demand influence medical services provider's location at the Mexican side of the border, a link that may be helpful to explain border complementarity dynamics.

In that context, how does regional health care needs shape medical services provider's location at the Mexican side of the border? The present analysis represents an effort to contribute in this direction.

\footnotetext{
${ }^{1}$ According to the author: people traveling abroad from the United States for medical care appear to do so not because it is a luxury or choice; rather, they travel because it provides healthcare options that some people would be otherwise unable to find or afford.

${ }^{2}$ Public policy decisions such as those set forth by the Affordable care act since 2010 are a clear example of such potential.

${ }^{3}$ The incidence of diabetes being a clear example of similar health outcomes in the us Mexico border region.

${ }^{4}$ Argument that endures particular relevance when considering chronic diseases common among borders residents such as diabetes.
} 


\section{Data and methods}

The main data source analyzed is the National Statistic Directory of Economic Units (DENUE), this is an official source published by the Instituto Nacional de Estadística y Geografía (Inegi, 2015) available in a cross section format that allows international comparability within the North American context, since businesses are organized according to the North American Industrial Classification System (NAICS), a common classification for Canada, the us and Mexico.

The investigation relies on the 2015 DENUE release, this source was selected because it allows identifying health care providers at Mexican cities adjacent to the border; in particular it is of interest for this analysis since it contains geographic information reference linked to the economic activity of the firm.

The geographic coverage of the study includes the 8 largest border urban centers ${ }^{5}$ and 6 border cities that given their strategic location also generate trans-border medical services demand. The cities considered are: Tijuana, reflecting the Tijuana-San Diego connection. Mexicali, to capture the Imperial Valley-Mexicali connection; Tecate, a city located adjacent to the border that attracts local residents; Playas de Rosarito and Ensenada where strong market forces make this traditional tourism centers in the Baja Peninsula, also attractive destinations for medical tourism arriving from California (Whiteman, 2011).

Nogales, a main Sonora border hub which captures dynamics from places in Arizona such as Tucson and Phoenix; San Luis Rio Colorado and Agua Prieta. Juarez, Chihuahua which interacts with El Paso; Piedras Negras and Acuña in the state of Coahuila which receive local demand from communities such as Eagle Pass, Uvalde and Del Río, Texas.

And three urban centers from Tamaulipas state: Nuevo Laredo, Reynosa and Matamoros. The relevance of these last Tamaulipas cities refers to the fact that they capture demand from an economically deprived region; challenged by a high poverty incidence which influence health care access: the lower Rio Grande valley in Texas, whose income levels are amongst the lowest in the us (Davies and Holz, 1992; Mier et al., 2008; Manzanares, 2013).

The analysis is conducted for firms under NAICs sector code 62 which corresponds to the Health Care and Social Assistance group. This sector includes 207633 establishments at the national scale, (Inegi, 2015) however a subset is built for the study area containing 29230 establishments at the Border state level and 13455 at the urban scale. The Health Care and Social Assistance sector includes establishments providing health care and social assistance for individuals (United States Census Bureau, 2012) ${ }^{6}$

To capture the firm's industrial activity at the greatest detail, a 6 digit country specific national industry codes is considered for a total of 4 subsectors, 18 industry groups, 30 industries and 64 country specific national industry codes. ${ }^{7}$ The Table 1 provides the hierarchical order employed and descriptive statistics by city.

\footnotetext{
${ }^{5}$ Largest refers in this study to Tijuana, Mexicali, Nogales, Juárez, Nuevo Laredo, Reynosa y Matamoros, in addition of being located adjacent to the border line share a metropolitan area with the us side. This cities represent $89 \%$ of the total study population.

${ }^{6}$ According to the United States Census Bureau (2012), the sector includes both health care and social assistance because it is sometimes difficult to distinguish between the boundaries of these two activities.

${ }^{7}$ The four subsectors are: 621 Ambulatory health care services, 622: Hospitals, 623: Nursing and residential care facilities and 624: Social assistance.
} 
Table 1: Classification structure and descriptive statistics for United States-Mexico border cities from the north american industrial classification system

\begin{tabular}{|c|c|c|c|c|c|}
\hline \multicolumn{2}{|c|}{ Hierarchical order } & \multicolumn{4}{|c|}{ Codes Structure } \\
\hline \multicolumn{2}{|c|}{ Sector } & \multicolumn{2}{|c|}{1} & & \\
\hline \multicolumn{2}{|c|}{ Subsector } & \multicolumn{2}{|c|}{4} & & \\
\hline \multicolumn{2}{|c|}{ Industry groups } & \multicolumn{2}{|c|}{18} & & \\
\hline \multicolumn{2}{|c|}{ Industry } & \multicolumn{2}{|c|}{30} & & \\
\hline \multicolumn{2}{|c|}{ Country specific national industry } & \multicolumn{2}{|c|}{64} & & \\
\hline & City & Firms & $\%$ & $\begin{array}{c}\text { Cummulative } \\
\%\end{array}$ & $\begin{array}{l}\text { Population* } \\
2016\end{array}$ \\
\hline 1 & Tijuana & 3669 & 27.3 & 27.27 & 1748062 \\
\hline 2 & Mexicali & 2164 & 16.1 & 43.35 & 1039258 \\
\hline 3 & Ciudad Juárez & 1922 & 14.3 & 57.64 & 1435762 \\
\hline 4 & Ensenada & 1154 & 8.6 & 66.21 & 527666 \\
\hline 5 & Reynosa & 1026 & 7.6 & 73.84 & 691575 \\
\hline 6 & Matamoros & 925 & 6.9 & 80.71 & 530780 \\
\hline 7 & Nuevo Laredo & 604 & 4.5 & 85.2 & 419267 \\
\hline 8 & Nogales & 463 & 3.4 & 88.64 & 248819 \\
\hline 9 & San Luis Río Colorado & 458 & 3.4 & 92.05 & 200461 \\
\hline 10 & Piedras Negras & 380 & 2.8 & 94.87 & 163141 \\
\hline 11 & Playas de Rosarito & 191 & 1.4 & 96.29 & 107095 \\
\hline 12 & Agua Prieta & 168 & 1.3 & 97.54 & 89137 \\
\hline 13 & Acuña & 166 & 1.2 & 98.77 & 147986 \\
\hline 14 & Tecate & 165 & 1.2 & 100 & 112604 \\
\hline & Total Firms & 13455 & 100 & & 7461613 \\
\hline
\end{tabular}

Population estimates by Consejo Nacional de Población (Conapo, n.d.).

Source: Own estimation DENUE (Inegi, 2015), United States Census Bureau (2012).

In addition, contextual reference on demographics is obtained for the us population at border based on the American Community Survey (ACS) (United States Census Bureau, 2015) public use micro data, ${ }^{8}$ a leading sociodemographic official source that is considered to evaluate background conditions on income as a determinant to health care access and insurance coverage. ${ }^{9}$

\footnotetext{
${ }^{8}$ The Acs conducted by the us Census Bureau offers three different formats for its sample files: A 1 year sample file containing information for year 2015, a 3 year sample for period 2011-2013 and a five year sample file for the period 2010-2014. In this study the 1 year 2015 sample data file was selected to capture the most recent demographic data, although this information is representative a geographic areas.

${ }^{9} \mathrm{As}$ a disclosure avoidance measure the most detailed unit of geography contained in the Acs PUM files is the Public Use Microdata Area (PUMA). Public Use Microdata Areas are special nonoverlapping areas that partition each state into geographic units containing no fewer than 100000 people each. Instead, to conduct a statistical representative analysis at regional level, Public Use Microdata Area geographies should be selected to match the region of study, as was the case for the present study, where a total of 66 PUMA are contained within the 61 mile area border definition.
} 


\section{Methods}

The analysis is organized in three stages: Exploratory data Analysis is conducted as a preliminary stage with the purpose of stablishing the background conditions in which regional demand for health care takes place in the us-Mexico border. In that first stage, two contextual variables are presented: income conditions as a proxy for access constrains and uninsured population shares as a complementary determinant resulting in cross border health care demand as documented by recent empirical studies conducted by $\mathrm{Su}$ et al., (2013); Grineski, Staniswalis, Peng \& Atkinson-Palombo (2010) and others.

Once local determinants are presented, the work proceeds to study health care providers spatial distribution at Mexican border cities, for that purpose a spatial concertation index (CI) is estimated according to the following specification.

$$
\mathrm{CI}=\frac{A}{B} . \text { Where: } \mathrm{A}=\frac{N_{\mathrm{i}}}{\sum_{621111}^{624412} N} ; \mathrm{B}=\frac{N_{\mathrm{i}}}{\sum_{621111}^{624412} N}
$$

Thus, index numerator A indicates the proportion that a particular NAICs classification code represents from the total number of firms within NAICs sector 62: Health Care and Social Assistance, which include industrial activity from code: 6211111 to activity 624412 as measured at the border city scale. Whereas expression B in the index denominator captures the corresponding proportion measured at the state scale.

Following the above algorithm, two threshold values result of interest for the index: $\mathrm{CI}>1$ values indicate a relative specialization for that category at the border city scale relative to the observed proportion at the state. Whereas a $\mathrm{CI}<1$, imply that the particular activity does not exhibit relative concentration at the border city scale. Although this approach has been widely applied in regional science and urban economics literature by a growing number of authors recently (Billings \& Johnson, 2012). the present study represent the first effort in Mexico to study medical services providers location at the us Mexico border at a local scale, in this case a postal code scale was achieved given the data geographic attributes.

A third analysis stage using geostatistical tools is conducted to represent the spatial distribution of establishments as determined by the concentration index for Tijuana, a city that represents virtually one in every three medical services establishments of the entire border $(27.3 \%)$ and is the largest city within the entire study. The goal in this stage is to inquire into the relation between medical services location and proximity to the border crossing.

In order to accomplish this stage an Empirical Bayesian Kriging (Евк) density estimation is conducted. This approach is a geostatistical interpolation method that allows creating a continuous surface based on the geographic location of each establishment in the data set. For a given distance $h$, empirical Bayesian kriging uses a semivariogram ${ }^{10}$ model with the following form:

\footnotetext{
${ }^{10}$ The semivariogram function relates known data locations as a function to distance. It depicts the spatial
} autocorrelation of the measured sample points. 


$$
\gamma(\mathrm{h})=\text { Nugget }+b|h|^{\alpha}
$$

Where $b$ is a slope parameter, the nugget represents the intercept, the power $\alpha$ is an adjustment parameter between (.25-1.75) and $h$ indicate a distance parameter. The semivariogram parameters in EBK are estimated using restricted maximum likelihood (REML), according to Pilz and Spöck (2008), this method takes into account the semivariogram function uncertainty providing an advantage over other kriging estimation methods such as weighted least squares (Pilz \& Spöck, 2008).

Furthermore, the statistical significance of the density pattern is validated by applying a hot spot analysis using the Getis Ord Index (GI) along with its associated z scores and $P$ values. The Getis-Ord (Gi) index has been extensively applied in empirical research by scientists to test or theorize about variables to determine whether spatial association, either observed or expected, actually can be confirmed (Getis, 2015).

The GI identifies those clusters of points with values higher in magnitude than might be expected to find in a given random distribution. The $\mathrm{z}$ score obtained considers a random distribution null hypothesis computation. Once the clustering pattern is statistically validated, the clusters identified are presented at the zip code scale.

\section{Exploratory data analysis}

As discussed earlier, income and poverty incidence are classic determinants for cross border health care demand by the us population into Mexican cities, however demographic structure per se constitutes a dominant force towards this trend.

Considering micro data from the Acs (United States Census Bureau, 2015), regarding the population structure, in areas of the border such as Texas where the higher percentage of older adult population is found, as much as $25 \%$ of the households indicate the presence of 1 person 65 years old and over, as compared to $13.74 \%$ in households living outside of the border (United States Census Bureau, 2015), a fact that indicate a latent need for health care services consistent with previous research efforts such as Magilvy, Congdon, Martínez, Davis \& Averill (2000), Gerts-Emerson, Shovali \& Markides (2014) among others.

Furthermore, basic expenditures such as rent, allocated by Spanish speaking population living in the border region, ${ }^{11}$ absorbs $28 \%$ of household income for families with a Male householder, whereas that figure increases to $38 \%$ for families with a female householder, a gap representing an additional pressure on the household budget for those families.

Under these circumstances basic life quality characteristics such as health care, become a challenge, hence strategies to overcome financial barriers to affordable health care access may appear in populations living at border proximities where medical services price differentials act as a social incentive providing alternatives to health care that motivates border regional integration.

\footnotetext{
${ }^{11}$ Individual border states figures are: Texas, the state where the biggest gap is found: 25 vs.37\%; California: 33 vs. $41 \%$; Arizona: 29 vs. $36 \%$; New Mexico: 25 vs. $36 \%$. Percentages for Male householder vs. Female respectively.
} 
Figure 1 below, presents an estimation of poverty conditions for individuals living at us border counties using the head count index defined by Foster Greer Thornbecke, (FGT) a standard measure in the poverty studies. Additionally the estimation on the right corresponds to poverty to income ratio for two different population segments including Mexican origin, a complementary measure that indicates the income burden within separate demographic segments.

Figure 1: Poverty levels at the United States-Mexico border
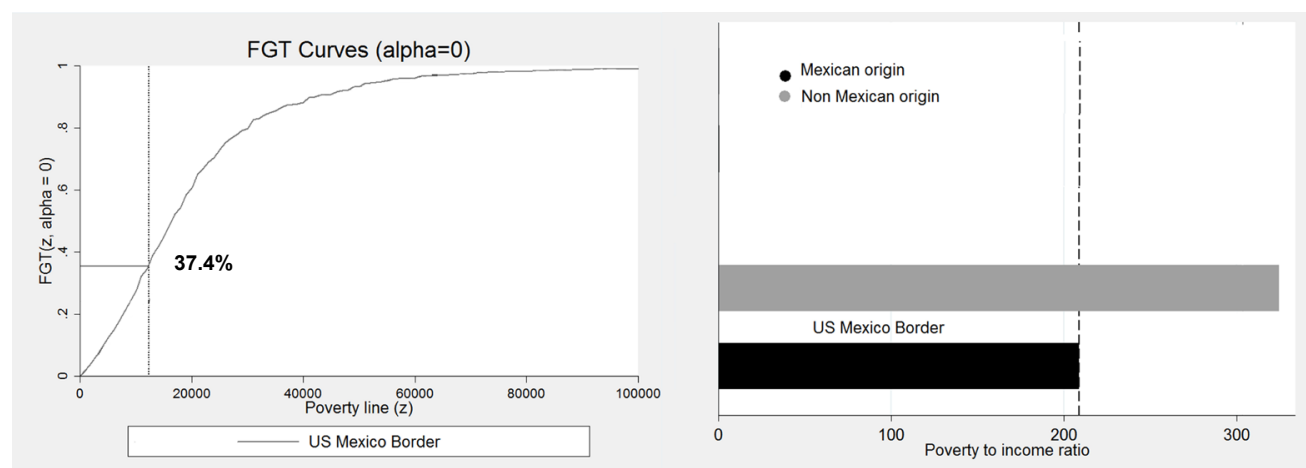

Note: Mexican origin refers to population born in Mexico, not us citizens. Income estimated by county based on Public Use Micro data areas: Border region defined as the area within 61 miles from border line. Poverty line \$12 316 according to us census Bureau 2014, defined for 1 person under 65.

Source: American Community Survey (United States Census Bureau, 2015).

To evaluate the possible presence of regional disparities Figure 2, present's uninsured us population at the Mexican border, this exploratory variable may be considered a proxy for potential cross border demand since it captures the magnitude of local health care needs.

The emerging pattern from the information above suggest that there are important health insurance coverage differences at the county level along us states at the Mexican border, with proportions of uninsured population as high as $43 \%$, issue that my translate into a factor influencing cross border medical services demand.

The uninsured population pattern found in the us Mexico border moves from West, where the lowest uninsured rates are found in counties such as San Diego, California, to the south east portion of the border towards the state of Texas where the highest proportions of uninsured population occurs.

Recent findings from other studies suggest a dynamic cross border demand for specialized medical services. According to Jabbari et al. (2015), in the southern region of San Diego County (California), up to $70 \%$ of oncology patients are Spanish speaking, with the majority having important social, economic, or health care ties across the border (Jabbari et al., 2015). 
Figure 2: Population without health insurance coverage (\% total). United States-México border, 2015

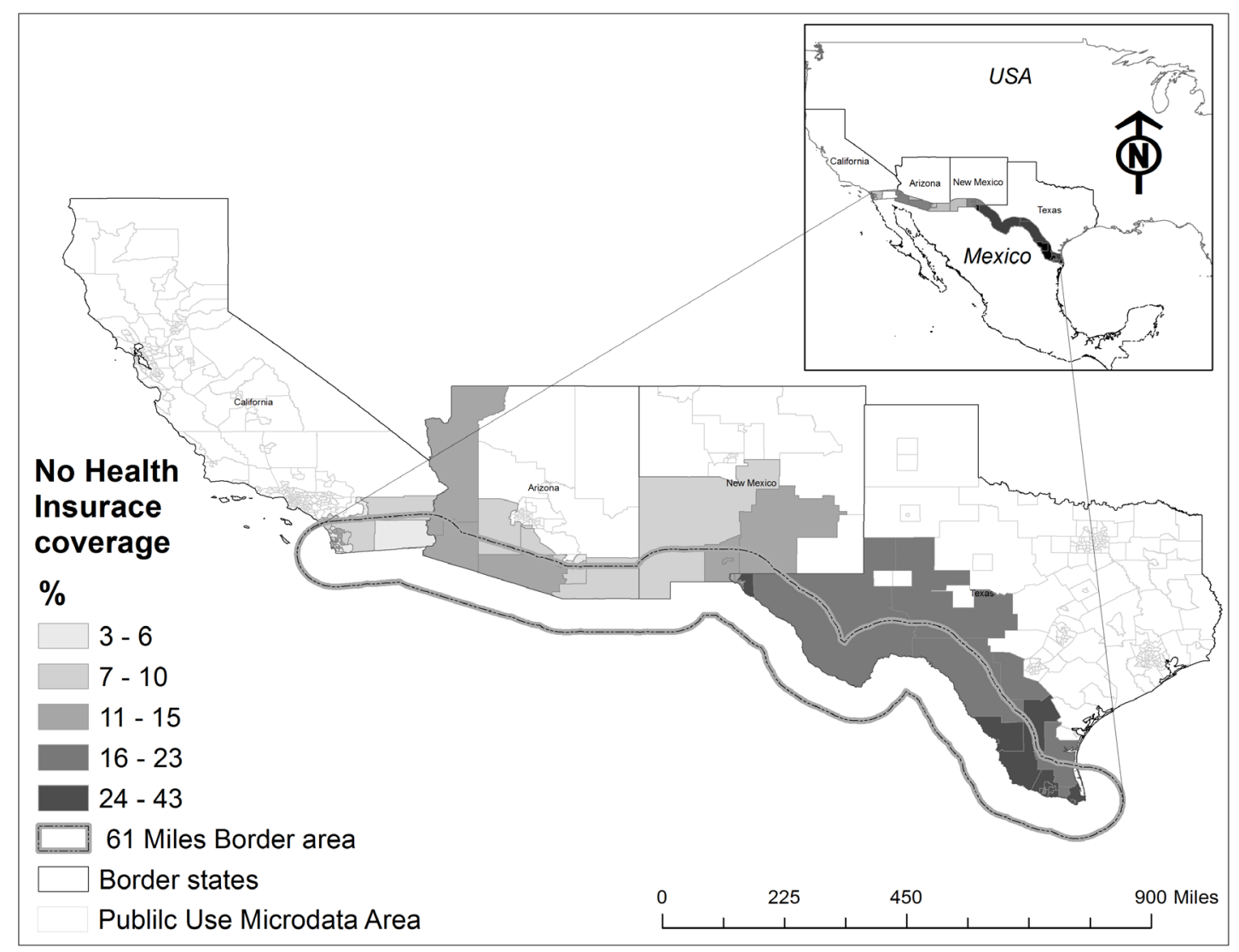

Note: us-Mexican border defined by the area within a 61 mile distance, from the international boundary line according to the standard border definition accepted by international institutions.

Source: American Community Survey (United States Census Bureau, 2015).

\section{Spatial distribution of health care providers at Mexican border cities}

In this section the spatial distribution of economic data on health care providers at Mexican border cities is presented using data from the national statistic directory of economic units (Inegi, 2015). The aim is to determine medical services providers' spatial location patterns as an expression of the social forces generating trans-border health care demand.

A preliminary frequencies estimation by NAIcs codes within sector 62: Health care and social assistance, shows that subsector Ambulatory health care service corresponding to NAICS code 621 , represents $76.29 \%$ of the establishments offering services at the study area. Within 621 subsector there are 7 industry groups, however only 3 industry groups concentrate the medical services activity, this are NAICs 621-Offices of physicians, NAICS 6212-Offices of dentists and NAICs 6215-Medical and diagnostic laboratories.

A second subsector of relative importance is NAICs code 624 which corresponds to social assistance represent almost 1 in 5 establishments in the area $(17.66 \%)$, this subsector includes the following 4 industry groups: 
6241: Individual and family services.

6242: Community food and housing, and emergency and other relief services.

6243: Vocational rehabilitation services and industry group.

6244: Child day care services.

Among these industry groups, NAICs codes 6244: Child day care services and 6241: Individual and family services, represent $90.28 \%$ of the establishments.

Apparently these industry groups are the core of medical services activities within the NAICS sector 62 at the border cities studied, however contrasting the relative concentration found at the city scale vs. the concertation prevalent at the state context may be useful to further establish medical services localization patterns and its relation to the social forces acting upon the study area.

A further examination for the frequencies by NaIcs code at industry level (6 digit code) considering the state and city scale reveals the following 10 most common health services provided at the Mexican border: private dental offices (code 621211), specialized private medical offices, (code 621113), general medicine private offices, (code 621111), private medical diagnostics labs, (code 621511), addictions and alcoholism self-help centers, (code 624191), nursery and day care centers, (code 624411), private psychology offices (code 621331). Other private health care offices (code 621398), private general hospitals, (code 622112), child day care services (code 624412).

Although the categories are virtually the same in both areas (state and city scale) the relative proportions in every category indicate a particularly interesting finding. Using the relative proportions in every category a spatial concertation index (CI) was constructed, this allows to measure the relative weight of every category between two geographic spaces, the index is normalized so values greater than unity indicate a relative concertation of a particular category in relation to the proportion observed at the state level. Using this approach, four industries are found with an over proportion in the border cities, this are: private dental offices (NAICs code 621211 ) $\mathrm{CI}=1.32$, general medicine private offices, (NAICS code 621111) $\mathrm{CI}=1.16$, private medical diagnostics labs, (NAICS code 621511$), \mathrm{CI}=1.02$, private general hospitals, (NAICS code 621398$) \mathrm{CI}=1.03$.

Thus, the concentration pattern arising when applying the CI approach reveals further details with a focus on specific activities. The following Table 2 presents the estimation summary.

It is confirmed that NAICS industry 621211 Private dental offices is a particularly relevant medical service for cities at the Mexican side of the border. Moreover, the CI estimation allows measuring the concentration degree at every city as shown by Figure 3 .

In addition to the overall specialization pattern found, in which NAICs industry code 621211 is dominant, a closer analysis of the cI estimated for the 6 larger border cities $^{12}$ in the study reveals the following specific specialization pattern, Tijuana: private offices of physicians, (621115) cI 1.46; Juarez: private specialized offices of physicians (621113), CI 1.35; Reynosa: medical and diagnostic laboratories (621511), CI 1.44; Ensenada: offices of mental health practitioners (621331) CI 2.33; Matamoros: (621112) public sector offices of physicians CI 2.42.

\footnotetext{
${ }^{12}$ From the spatial perspective, six cities in the studied group concentrate $80.71 \%$ of the medical services activity, this cities are Tijuana, Mexicali, Juarez, Ensenada, Reynosa and Matamoros. This subset of cities being the most populated in the study area show the close link between economic activity and city size.
} 
Table 2: Concentration index $\mathrm{Cl}$. Top 10 industries by frequency

\begin{tabular}{ccccccc} 
Position & NAICS code & Freq. City & Percent & Freq. State & Percent & CI \\
\hline $1^{*}$ & 621211 & 3993 & 29.68 & 3540 & 22.44 & 1.32 \\
\hline 2 & 621113 & 2270 & 16.87 & 2852 & 18.08 & 0.93 \\
\hline $3^{*}$ & 621111 & 2140 & 15.9 & 2148 & 13.62 & 1.16 \\
\hline $4^{*}$ & 621511 & 794 & 5.9 & 909 & 5.76 & 1.02 \\
\hline 5 & 624191 & 687 & 5.11 & 1094 & 6.94 & 0.74 \\
\hline 6 & 624411 & 678 & 5.04 & 969 & 6.14 & 0.82 \\
\hline 7 & 621331 & 334 & 2.48 & 435 & 2.76 & 0.90 \\
\hline $8^{*}$ & 621398 & 285 & 2.12 & 324 & 2.05 & 1.03 \\
\hline 9 & 622112 & 204 & 1.52 & 499 & 3.16 & 0.48 \\
\hline 10 & 624412 & 192 & 1.43 & 393 & 2.49 & 0.57 \\
\hline
\end{tabular}

* Values greater than 1 indicate a relative specialization in that category for border city $i$ Relative to the observed proportion at the state.

Source: Own estimation DENUE (Inegi, 2015).

Figure 3: Concentration Index for North American Industrial Classification System industry code 621211: Private dental offices by border city

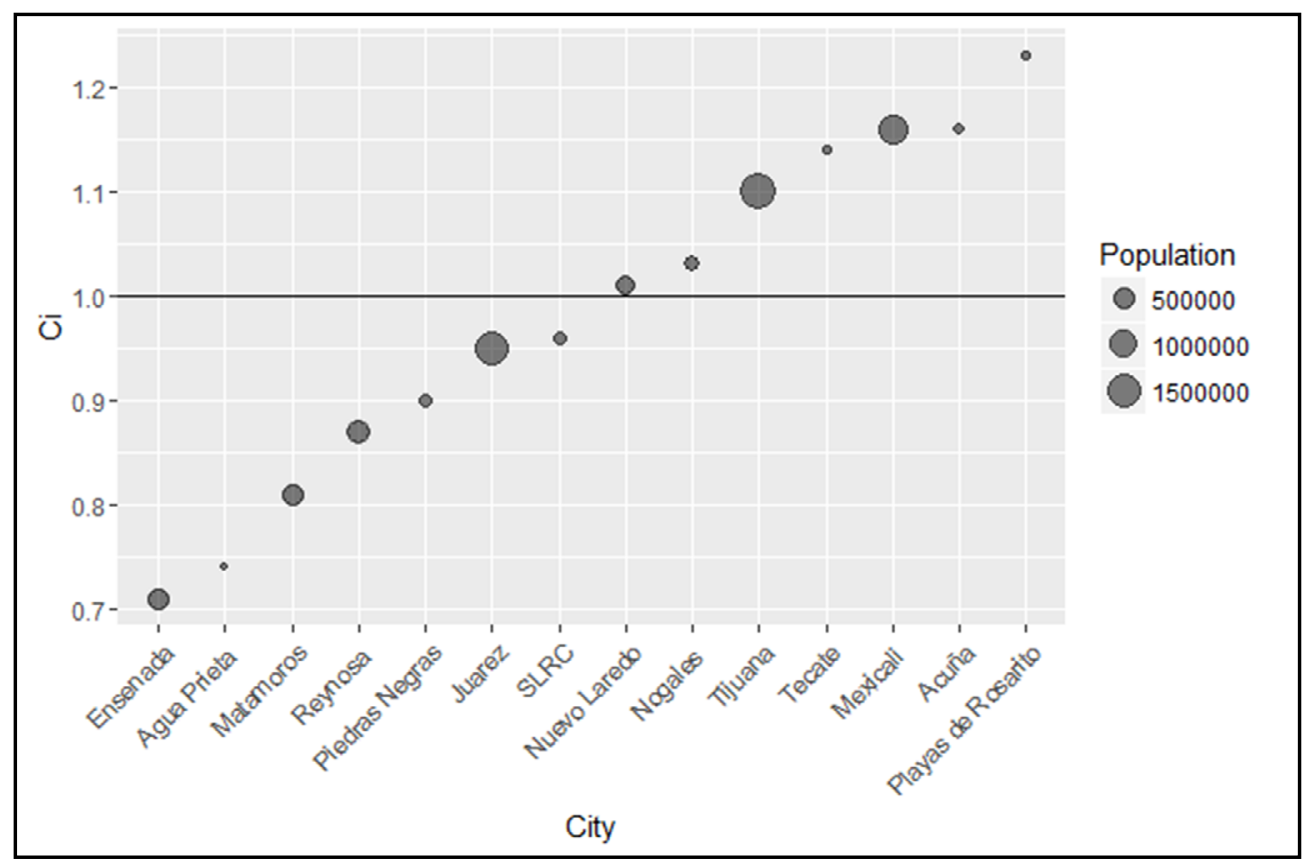

Note: $\mathrm{Cl}>1$ values indicate relative concentration in that city relative to the state level. Source: Own estimation DENUE (Inegi, 2015). 
In order to analyze the geographic distribution of medical services at the urban scale in relation to the city's border crossings, Empirical Bayesian Kriging (ЕВк) density estimation is conducted considering the larger city in the study area (Tijuana). ${ }^{13}$ This approach allows creating a continuous surface along the urban space based on the geographic location of each establishment in the data set to identify any cluster patterns (Figure 4).

Figure 4: Tijuana urban area medical services sector establishment distribution

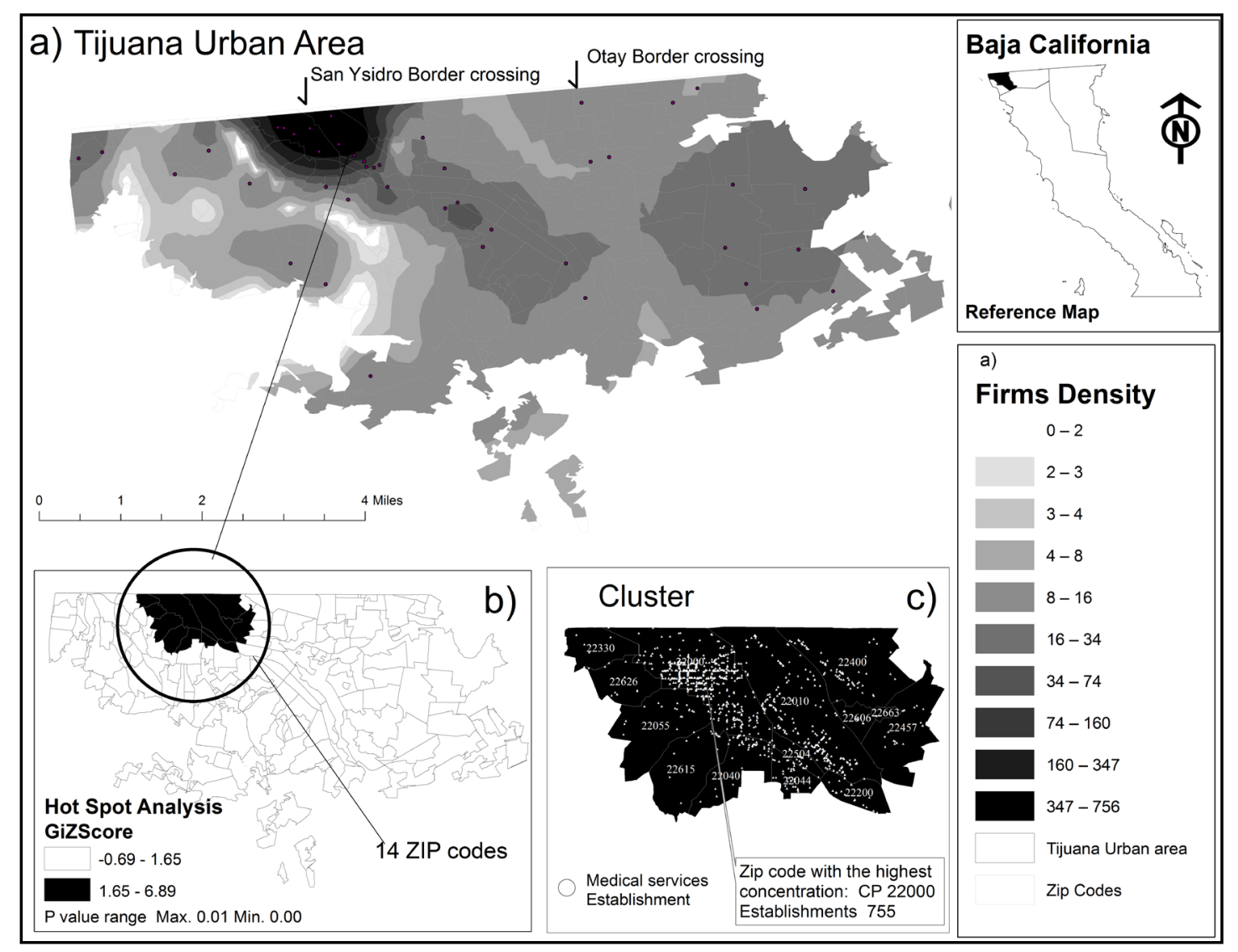

Note: $\mathrm{P}$ value and $\mathrm{Gi} z$ scores indicate the presence of a statistical significant high clustering. Source: Own estimation DENUE (Inegi, 2015).

As shown in Figure 4, map a) revealed results from the empirical Bayesian Kriging density estimation, the empirical density pattern found suggest the existence of a cluster of medical services establishments around the San Ysidro border crossing, interestingly this clustering pattern is not observed at the Otay Border crossing. In map $b$ ) a statistical test for the observed density pattern is conducted, this allows to determine the existence of statistical significance cluster areas for medical services establishments, result confirms the presence of a cluster just around the San Ysidro border

\footnotetext{
${ }^{13}$ This city captures virtually one in every three medical services establishments (27.3\%) of the entire study with 3669 establishments.
} 
crossing. ${ }^{14}$ Map $c$ ) present the cluster at the zip code scale, the area found includes 14 zip codes just around the San Ysidro Border crossing.

\section{Discussion and conclusion}

As pointed by Su et al. (2013) the quantity, quality, accessibility, and affordability of health care resources are all specific to a certain geographic location. Considering this premise the perspective adopted to conduct the exploratory data analysis in the first stage of this investigation primarily focused on the latter two determinants and results on income profiles and uninsured population shares as a proxy for health care access constrains at the us side of the border indicate the existence of social conditions that foster cross border medical services demand. Apparently these social determinants combined with the presence of strong market forces previously documented by Bastida et al. (2008) such as medical services price differentials, seems to result in a social incentive providing alternatives that motivates patients to frequently cross the border into Mexico to demand health care services, argument in line with recent empirical evidence also explored by authors such as Jabbari et al. (2015) among others.

The preliminary analysis results indicate that demographic structure at the border per se constitutes a dominant force towards observed cross border medical services demand. Regarding the population structure, it was found that as much as $25 \%$ of the households at some border areas indicate the presence of 1 person 65 years old and over, as compared to $13.74 \%$ in households living outside of the border (United States Census Bureau, 2015), a fact that confirms a latent need for health care services consistent with previous research efforts such as Magilvy et al. (2000), Gerts-Emerson Shovali \& Markides (2014).

Once the analysis stage on health care providers spatial distribution at Mexican border cities was conducted several important issues were revealed. First within the NAICs hierarchical structure for sector 62 corresponding to the Health care and social assistance the focus of attention pointed to subsector NAICs code 621: Ambulatory health care service since it represents $76.29 \%$ of the establishments offering services at the study area.

Within this subsector and with support of the proposed concentration index CI, it was possible to identify that four activities show a relative concertation at the border city scale: private dental offices (NAICS code 621211 ) CI $=1.32$, general medicine private offices (NAICS code 621111) $\mathrm{CI}=1.16$, private medical diagnostics labs (NAICS code $621511) \mathrm{CI}=1.02$, and private general hospitals (NAICS code 621398) $\mathrm{CI}=1.03$.

Although, the analysis distinguish other important activities such as Child day care services (NAICS code 624412). A preliminary conjecture as supported by recent studies on this structure may be attributed to the intense maquiladora activity present in the area, which generates demand for this type of services. The evidence found in this regard, agrees with scholars studying women daily mobility at the border cities such as Hansen (2006), whose arguments highlight that, child care services represent an important issue for women's daily mobility at the us Mexico border cities; however further studies may be needed to inquire into this link.

\footnotetext{
${ }^{14}$ The $z$ score for the Getis Ord Index in the cluster all exceed 1.65 with at the 0.05 significance level.
} 
In addition, the Concentration Index, (CI) estimation provided a relative contrast measure to determine medical services activity for every city. This evidence of a particular specialization patterns in each city may be useful to implement public policy measures to support those specific consumptions activities at the local level. In this regard the case for NAICs industry code 621211: Private dental offices seems a priority with opportunities to improve relevant service attraction attributes such as quality, given the natural demand already present in the study area.

Furthermore, findings from the spatial analysis conducted at the biggest city in the study show that medical services activity exhibits a cluster pattern around a border crossing (вС); the San Ysidro вс. Moreover a clear difference of clustering patterns is found between border crossings, while the San Ysidro BC shows a clear clustering pattern, the Otay BC does not exhibit this spatial correlation, this result may just reflect the border crossings type, while the former is the main commercial area and receives regular traffic the latter is oriented towards freight and has lower pedestrian and regular vehicle traffic.

The empirical Bayesian Kriging density estimation, was confirmed by the hot spot methodology and a cluster integrated by 14 zIP codes representing only $7 \%$ of the Tijuana urban area surrounding the San Ysidro вс could be determined as statistically significant; that specific geographic area is responsible for $52 \%$ of the total number of medical services firms in the entire city. These findings suggest a possible line of research to study the spatial distribution of the specific activities found for every city to determine whether the clustering pattern around the border crossing changes depending on the border city.

Although the geographic reference associated to medical services activities implied by the main data source DENUE mean a qualitative improvement to study location patterns at the us Mexico border, a possible limitation identified in this study recognizes that regular updating methods will be desirable to keep the accuracy of DENUE, since it has been documented by the firms dynamics literature a high rate of firms mortality for short periods of times. Despite this fact the overall medical services pattern found seems consistent across the spatial area considered in the present study.

\section{Conclusion}

The growing medical service sector in the Mexican cities adjacent to the us border has been increasingly becoming a focus of attention for scholars and policy makers, whose efforts documented that particular health care needs arising from existing and developing health treats contribute to an increasing drift towards binational integration in health care across the us-Mexico border (Jabbari et al., 2015).

The present study, constitutes a first effort to understand how the medical services demands, triggered by contextual social factors at the us-Mexico border, influence medical services provider's location at the Mexican side of the border and translate into specific locational patterns that define the Mexican border cities today. The approach presented in this study challenges the borderlands traditional conceptualization centered on administrative and political limits, rather in this perspective regional health care needs constitute a link to explain border complementarity dynamics. 
Findings based on local level georeferenced data revealed specific medical services activities concentration at Mexican border cities and allow identifying spatial patterns that support a view of the border as a complement rather than as a barrier in which health needs and economic opportunities interact building border integration mechanisms.

\section{References}

Andersen, R. \& Newman, J. F. (2005). Societal and individual determinants of medical care utilization in the United States. Milbank Quarterly, 83(4), 111-112.

Anzaldúa, G. (1999). Borderlands. La Frontera: The New Mestiza (2 ${ }^{\text {nd }}$ ed.). San Francisco, United States: Spinsters, Aunt Lute Books.

Bastida, E., Brown, H. S. 3rd \& Pagán, J. A. (2008). Persistent disparities in the use of health care along the us-Mexico border: an ecological perspective. American Journal Public Health, 98(11), 1987-1995.

Billings, S. B. \& Johnson, E. B. (2012). The location quotient as an estimator of industrial concentration. Regional Science and Urban Economics, 42(4), 642-647.

Bustamante, A. V., Laugesen, M., Caban, M., \& Rosenau, P. (2012). United States-Mexico cross-border health insurance initiatives: Salud Migrante and Medicare in Mexico. Pan American Journal of Public Health, 31(1), 74-80.

Clemans-Cope, L., Long, S. K., Coughlin, T. A., Yemane, A. \& Resnick, D. (2013). The expansion of medicaid coverage under the ACA: Implications for health care access, use, and spending for vulnerable low-income adults. Inquiry, 50(2), 135149.

Consejo Nacional de Población (Conapo). (n.d.). Municipios 2010/2030. Retrieved from https://datos.gob.mx/busca/dataset/proyecciones-de-la-poblacion-de-mexico/resource/fd942023-03ee-418c-8129-c548dd98cfa1

Damianov, D. \& Pagán, J., (2013). Health insurance coverage, income distribution and healthcare quality in local healthcare markets. Health Economics, 22(8), 987-1002.

Davies, C. S. \& Holz, R. K. (1992). Settlement evolution of 'colonias' along the us-Mexico border: The case of the Lower Rio Grande Valley of Texas. Habitat International, 16(4), 119-142.

Escarce, J. J. \& Kapur, K. (2006). Access to and quality of health care. In M. Tienda \& M. Faith (Eds.), Hispanics and the future of America (pp. 410-446). Washington, District of Columbia, United States: The National Academies Press.

Footman, K., Knai, C., Baeten, R., Glonti, K. \& McKee, M. (2014). Cross-border health care in Europe 2014. Europe: World Health Organization.

Gerst-Emerson, K., Shovali, T. E. \& Markides, K. S. (2014). Loneliness among very old Mexican Americans: Findings from the Hispanic established populations epidemiologic studies of the elderly. Archives of Gerontology and Geriatrics, 59(1), 145-149.

Getis, A. (2015). Spatial Association, Measures of A2-Wright. In J. D. Write (Ed.), International Encyclopedia of the Social \& Behavioral Sciences $\left(2^{\text {nd }}\right.$ ed.). Amsterdam, Netherlands: Elsevier.

Grineski, S. E., Staniswalis, J. G., Peng, Y. \& Atkinson-Palombo, C. (2010). Children's asthma hospitalizations and relative risk due to nitrogen dioxide $\left(\mathrm{NO}_{2}\right)$ : Effect modification by race, ethnicity, and insurance status. Environmental Research, 110(2), 178-188. 
Hansen, E. R. (2006).Women's daily mobility at the us-Mexico Border. In D.J. Mattingly \& E. R. Hansen (Eds.), Women and change at the U.S.-Mexico border: Mobility, labor, and activism (pp. 36-38). Arizona, United States: The University of Arizona Press.

Instituto Nacional de Estadística y Geografía (Inegi). (2015). DENUE, Actividad económica. Servicios de salud y de asistencia social. Retrieved from http://www.beta.inegi.org. $\mathrm{mx} / \mathrm{app} / \mathrm{descarga/ficha.html?tit=388 \& ag=0}$

Jabbari, S., Fitzmaurice, T., Munoz, F., Lafuente, C., Zentner, P. \& Bustamante, J. G. (2015). Cross-border collaboration in oncology: A model for United States-Mexico border health. International Journal of Radiation Oncology Biology Physics, 92(3), 509-511.

Krueger, P. M., Bhaloo, T. \& Vaillancourt, P. (2009). Health Lifestyles in the United States and Canada: Are We Really So Different? Social Science Quarterly, 90(5), 1380-1402.

Magilvy, J. K., Congdon, J. G., Martínez, R. J., Davis, R. \& Averill, J. (2000). Caring for our own: Health care experiences of rural hispanic elders. Journal of Aging Studies, 14(2), 171-190.

Manzanares, J. L. (2013). Pobreza y uso de seguro médico entre la población de origen mexicano en la frontera: la región del valle del rio grande Texas. Análisis Económico, xVII, 219-240.

Maril R., (1989). Poorest of Americans: The Mexican-Americans of the lower valle del Rio Grande of Texas. United States: University of Notre Dame Press.

McKee, M. \& Belcher, P. (2008). Cross border health care in Europe. British Medical Journal, 337(7662), 124-125.

Mier, N., Ory, M. G., Zhan, D., Conkling, M., Sharkey, J. R. \& Burdine, J. N. (2008). Health-related quality of life among Mexican Americans living in colonias at the Texas-Mexico border. Social Science E Medicine, 66(8), 1760-1771.

Ortiz, L., Arizmendi, L., \& Cornelius L. J. (2004). Access to health care among Latinos of Mexican descent in colonias in two Texas counties. Journal Rural Health, 20(3), 246-252.

Pilz, J. \& Spöck, G. (2008). Why do we need and how should we implement Bayesian kriging methods. Stochastic Environmental Research and Risk Assessment, 22(5), 621-632.

Rosaldo, R. (1993). Culture and truth: The remaking of social analysis. Boston, United States: Beacon Press.

Sassen, S. (2013). When territory deborders territoriality. Territory, Politics, Governance, 1(1), 21-45. doi: 10.1080/21622671.2013.769895

Sohn, C. \& Lara-Valencia, F. (2013). Borders and cities: perspectives from North America and Europe. Journal of Borderland Studies, 28(2), 181-190.

Su, D., Pratt, W., Salinas, J., Wong, R. \& Pagán, J. A. (2013). Rural-urban differences in health services utilization in the us-Mexico border region. The Journal of Rural Health, 29(2), 215-223.

Tscheulin, D. \& Drevs, F. (2007). Europe and health: national health care systems and the effects of European integration. Journal for Public and Nonprofit Services, 30(4), 436-448.

United States Census Bureau. (2012). Sector 11-Agriculture, Forestry, Fishing and Hunting. Retrieved from https://www.census.gov/eos/www/naics/2012NAICS/2012_ Definition_File.pdf 
United States Census Bureau. (2015). American Community Survey (ACS). Retrieved from https://www.census.gov/programs-surveys/acs

Wallace, S. P., Mendez-Luck, C. \& Castañeda, X. (2009). Heading South: Why Mexican Immigrants in California Seek Health Services in Mexico. Medical Care, 47(6), 662-669.

Whiteman, R. G. (2011). Medical tourism and bariatric surgery. Surgery for Obesity and Related Diseases, 7(5), 652-654.

José Luis Manzanares Rivera

Mexican. Doctor of Economics, graduated from UAM, UACJ, UABC. Researcher at El Colegio de la Frontera Norte, in the Departamento de Estudios Urbanos y del Medio Ambiente. Reserach lines: quantitative analysis applied to the relationship: economy, environment, health. Recent publications: Manzanares, J. L. (2016). Calidad de los recursos hídricos en el contexto de la actividad económica y patrones de salud en Sonora, México. Salud colectiva, 12(3), 397-414. 